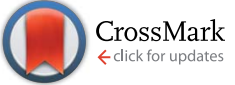

Cite this: Chem. Sci., 2015, 6, 209

Received 19th September 2014 Accepted 22nd September 2014

DOI: $10.1039 / c 4 s c 02882 a$

www.rsc.org/chemicalscience

\section{Regulating signal enhancement with coordination- coupled deprotonation of a hydrazone switch $\dagger$}

\author{
Justin T. Foy, ${ }^{a}$ Debdas Ray ${ }^{\mathrm{b}}$ and Ivan Aprahamian*c \\ Proton relay plays an important role in many biocatalytic pathways. In order to mimic such processes in the \\ context of molecular switches, we developed coordination-coupled deprotonation (CCD) driven signaling \\ and signal enhancement sequences. This was accomplished by using the zinc(I)-initiated CCD of a \\ hydrazone switch to instigate an acid catalyzed imine bond hydrolysis that separates a quencher from a \\ fluorophore thus leading to emission amplification. Because CCD is a reversible process, we were able \\ to show that the catalysis can be regulated and turned "on" and "off" using a metalation/demetalation cycle.
}

\section{Introduction}

Signal transduction in biological systems relies on receptors that respond to specific inputs in the environment, and then use catalytic reactions to amplify the signal into useful information. ${ }^{1}$ This complex signaling network is regulated by reversible feedback mechanisms that switch their activity "on" and "off" to maintain homeostasis. ${ }^{2}$ Recently, there has been interest in designing multicomponent systems ${ }^{3}$ that use signaling cascades, whereupon one molecule acts as the input to another, as a method towards mimicking the complexity ${ }^{4}$ of biological processes. Such research is expected to shed light on the origins of life, ${ }^{5}$ and lead to molecular computing, ${ }^{6}$ and systems chemistry, ${ }^{7}$ among other developments. Molecular switches and machines ${ }^{8}$ have been pursued in this context as enzyme mimics that are capable of controlling through their reversible, stimuli-dependent (mainly light) processes, the active sites of catalysts. ${ }^{9}$ In doing so, these systems mimic the regulatory activity demonstrated by enzymes.

We have recently developed hydrazone-based rotary switches $^{\mathbf{1 0}}$ that undergo configurational switching (i.e., $E / Z$ isomerization) through a bio-inspired, zinc(II)-initiated coordination-coupled deprotonation (CCD) process. ${ }^{\mathbf{1 0 d}}$ We have also demonstrated that CCD can be used in activating two different switches through a sequence of proton relays. ${ }^{10 f}$ We reasoned that the CCD induced reversible acid formation could be used to drive a catalytic hydrolysis reaction, similar to what is observed

${ }^{a}$ SAMS Research Group, University of Strasbourg, Institut Charles Sadron, CNRS, 23 rue du Loess, BP84047, 67034, Strasbourg Cedex 2, France

${ }^{b}$ Department of Chemistry, School of Natural Sciences, Shiv Nadar University, Chithera, Tehsil Dadri, Gautam Budh Nagar-203207, Uttar Pradesh, India

${ }^{\circ}$ Department of Chemistry, Dartmouth College, 6128 Burke Laboratory, Hanover, NH, USA 03755. E-mail: ivan.aprahamian@dartmouth.edu

$\dagger$ Electronic supplementary information (ESI) available. CCDC 862857 and 990962. For ESI and crystallographic data in CIF or other electronic format see DOI: $10.1039 / \mathrm{c} 4 \mathrm{sc} 02882 \mathrm{a}$ in many biological signaling pathways (e.g. GTPases and phospholipases), ${ }^{1}$ to yield signal enhancement (Scheme 1). ${ }^{\mathbf{1 1 , 1 2}}$ Herein, we demonstrate how the proton released in CCD can be used in mimicking such processes through the acid catalyzed hydrolysis of anthracen-9-yl- $N$-(4-nitrophenyl)methanimine ${ }^{13}$ (ANI). Furthermore, we show that the imine hydrolysis (i.e., catalysis) can be toggled "on" and "off" through metalation/ demetalation cycles.

\section{Results and discussion}

The ${ }^{1} \mathrm{H}$ NMR spectrum of $\mathbf{1}(\boldsymbol{E})$ (ref. 14) (Fig. 1b) shows the presence of two deshielded resonances at $\delta=15.22$ and 11.39 ppm, originating from the intramolecularly H-bonded hydrazone and imidazolyl protons, respectively. The crystal structure of $\mathbf{1}(\boldsymbol{E})$ (Fig. 2a) ${ }^{15}$ also shows the existence of the intramolecular $\mathrm{H}$-bond between the hydrazone $\mathrm{NH}$ proton and quinolinyl (N3)

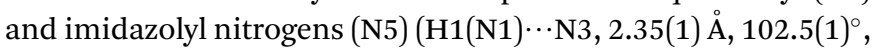
and $\mathrm{H} 1(\mathrm{~N} 1) \cdots \mathrm{N} 5,1.93(1) \AA, 135.8(1)^{\circ}$, respectively). The ester
$1(E)$

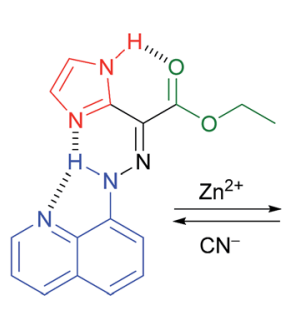

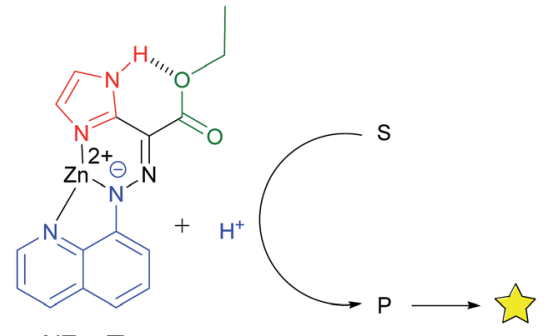

$1(\mathrm{Zn}-E)$
Scheme 1 The imidazolyl containing switch $1(E)$ undergoes CCD upon addition of zinc(II) resulting in the release of a proton to the environment. The acidification of the solution can be used to turn "on" $\mathrm{pH}$-sensitive dyes ( $\rightarrow \mathrm{P}$ ), which lead to fluorescence output. The coupling of this process to a catalytic cycle leads to signal amplification. This process is reversible as the molecular switch $1(Z n-E)$ can be deactivated through demetalation. 
a)

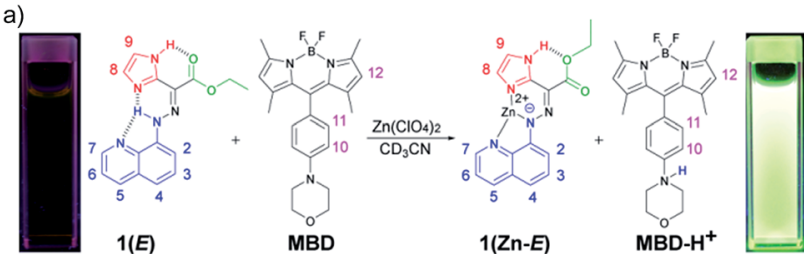

b) $1(E)$ and MBD

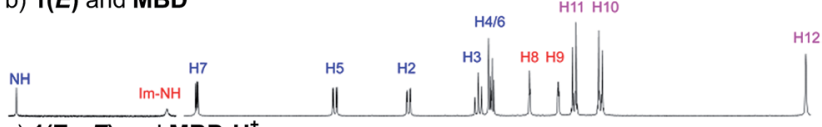

c) $1(\mathrm{Zn}-\mathrm{E})$ and $\mathrm{MBD}-\mathrm{H}^{+}$
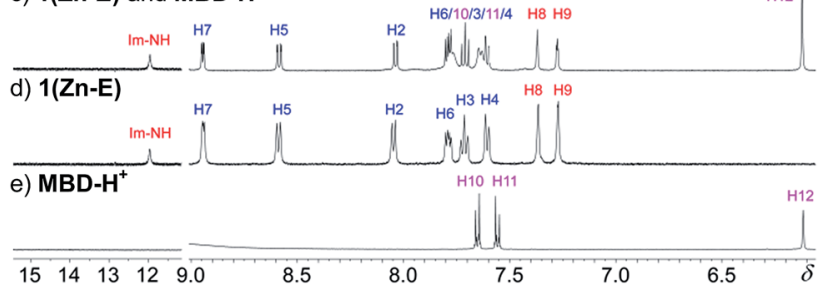

Fig. 1 (a) The compounds involved in the CCD initiated signaling event that turns "on" the emission of MBD. The ${ }^{1} \mathrm{H}$ NMR spectra $(500 \mathrm{MHz}$, $\mathrm{CD}_{3} \mathrm{CN}$ ) of (b) $1(E)$ and MBD (1:1 mixture); (c) $1(\mathrm{Zn}-E)$ and MBD- $\mathrm{H}^{+}$ obtained after the addition of 1 equiv. of zinc(II); (d) dissolved crystals of $1(Z n-E)$; and (e) MBD- $\mathrm{H}^{+}$obtained after addition of TFA ( 8 equiv.) to MBD. a)

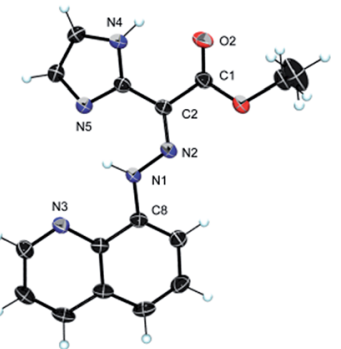

b)

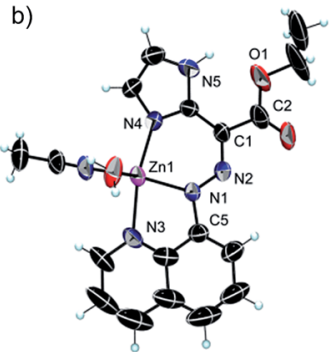

Fig. 2 ORTEP drawings (50\% probability ellipsoids) of (a) $1(E)$ and (b) $1(Z n-E)$. The protons are placed in calculated positions, except for those of the hydrazone N(1) atom, the imidazolyl nitrogen atoms N(4)/ $N(5)$, and the water molecule, which were refined. The counter ion of $1(Z n-E)$ is not shown for clarity.

carbonyl oxygen also forms an intramolecular hydrogen bond with the imidazolyl $\mathrm{NH}$ proton $(\mathrm{H} 4(\mathrm{~N} 4) \cdots \mathrm{O} 2,2.21(1) \AA$, $\left.117.9(1)^{\circ}\right)$. This additional intramolecular H-bond changes the outcome of zinc(II)-initiated CCD in $\mathbf{1}(E)$ : instead of an instantaneous $E \rightarrow Z$ isomerization upon coordination to zinc(II) ${ }^{10 d f}$ the intramolecular H-bond locks the system in its $E$ configuration to form $\mathbf{1}(\mathbf{Z n}-E)$. This process was monitored and characterized using ${ }^{1} \mathrm{H}$ NMR spectroscopy (Fig. S5 in ESI $\dagger$ ), which shows the disappearance of the hydrazone $\mathrm{NH}$ proton, and an up-field shift of the imidazolyl NH signal $(\delta=11.93 \mathrm{ppm})$ upon coordination with zinc(II). Analysis of the crystal structure of 1(Zn-E) (Fig. 2b) ${ }^{16}$ reveals a shorter intramolecular H-bond between the imidazolyl $\mathrm{NH}$ proton and ester oxygen (H5(N5) ‥O1, 2.03(1) $\left.\AA, 123.9(1)^{\circ}\right)$. The binding of zinc(II) with $\mathbf{1}(E)$ was also studied using UV/Vis spectroscopy (Fig. S25-S27 in ESI $\dagger$ ). A Job's plot analysis showed a 1:1 binding stoichiometry between $1(E)$ and zinc(II), with a binding constant of $K_{\mathrm{a}}=1.6 \times$ $10^{4} \mathrm{M}^{-1}$.

During the titration of $\mathbf{1}(\boldsymbol{E})$ with zinc(II) (Fig. S8 in ESI $\dagger$ ) we observed that CCD was accompanied by the protonation of noncoordinated $\mathbf{1}(E)$. In order to put the released proton to better use (and simplify the characterization process), the CCD initiated process was coupled with a newly developed $\mathrm{pH}$-responsive fluorophore ${ }^{17}$ (morpholinyl-containing BODIPY (MBD)), which resulted in the turn "on" of its fluorescence emission (Fig. 1a). ${ }^{18}$ ${ }^{1} \mathrm{H}$ NMR spectroscopy analysis showed that the addition of 1 equiv. of zinc(II) to a 1:1 mixture of $\mathbf{1}(E)$ and MBD (Fig. 1b) yields $\mathbf{1}(\mathbf{Z n}-\boldsymbol{E})$ and the protonated $\mathbf{M B D}$ compound $\left(\mathbf{M B D}-\mathbf{H}^{+}\right)$ (Fig. 1c). The formation of the former was confirmed by comparing the spectrum obtained via CCD to the one obtained by the dissolution of crystals used in the X-ray crystallographic analysis of $\mathbf{1}(\mathbf{Z n}-\boldsymbol{E})$ (Fig. 1d). The formation of $\mathbf{M B D}-\mathbf{H}^{+}$, on the other hand, was confirmed by protonating MBD separately with TFA (Fig. 1e). As can be seen in Fig. 1c protonation causes a downfield shift of the phenyl signals of MBD; from $\delta=7.17$ (H11) and 7.05 (H10) ppm in the neutral form, to $\delta=7.63$ (H11) and 7.78 (H10) ppm in the protonated one. No such shifts are observed when zinc(II) is added to MBD (Fig. S32 in ESI $\dagger$ ) confirming that protonation results from CCD.

This intermolecular proton relay was also probed using fluorescence spectroscopy (Fig. 3). Initially, the fluorescence is quenched most likely because of twisted intramolecular charge transfer. ${ }^{17}$ Upon titration of zinc(II) into a $1: 1$ mixture of MBD and $\mathbf{1}(E)$, a steady ratiometric increase in fluorescence intensity $(\lambda=522 \mathrm{~nm})$ was observed as a result of the protonation of MBD. The effect reached saturation when 1 equiv. of zinc(II) was added to the solution (Fig. 3, inset), resulting in a 1000-fold increase in emission intensity. ${ }^{19} \mathrm{~A}$ limit of detection (LOD) of $3.9 \mu \mathrm{M}$ was determined using this CCD initiated signaling mechanism (Fig. S28 in ESI $\dagger$ ). ${ }^{20}$

pH-Responsive fluorophores ${ }^{17}$ have been extensively used in sensing and molecular logic applications, and hence, the above

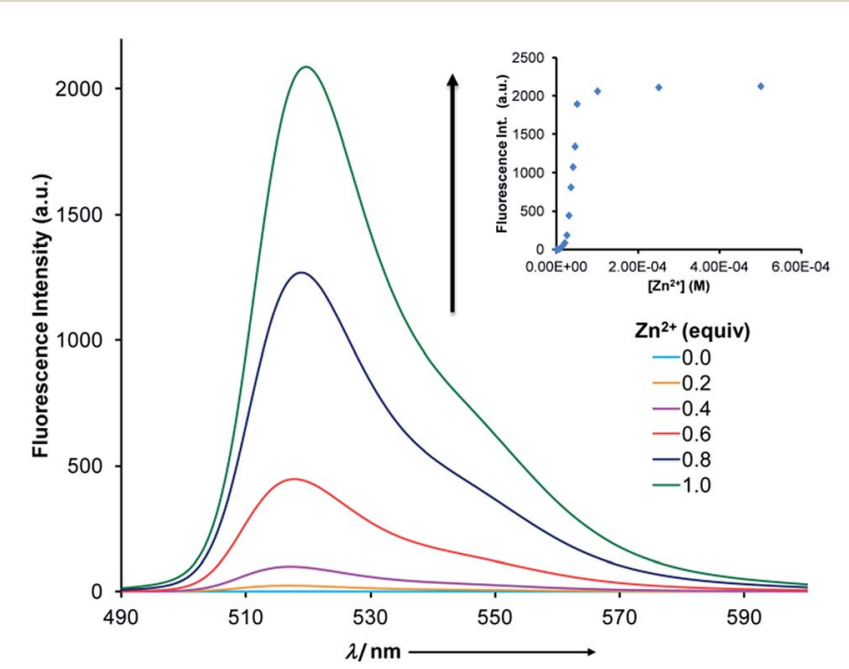

Fig. 3 Fluorescence spectra $\left(5 \times 10^{-5} \mathrm{M}, \mathrm{CH}_{3} \mathrm{CN}\right)$ of a $1: 1$ mixture of $1(E)$ and $M B D$ as a function of zinc(II) equivalents. The inset shows the 1000 -fold increase in emission intensity. 
mentioned results are not unexpected. ${ }^{6}$ However, in most cases the signaling event in such processes relies on one input leading to one output, which is not suitable for designing multicomponent signaling networks. ${ }^{3}$ In order to expand the scope of our system (i.e., using a single input in generating multiple outputs) and show its ability to reversibly control a catalytic process we explored the potential of coupling the CCD initiated signaling event with an amplification mechanism. We hypothesized that the acid catalyzed hydrolysis of an imine bond could be used to detach a quencher group from a fluorophore. For this purpose, we chose the weakly fluorescent dye ANI, which we speculated will undergo catalytic hydrolysis that will detach the $p$-nitrophenyl quencher ${ }^{21}$ and yield the more fluorescent anthraldehyde emitter (Fig. 4a).

This catalytic process was studied using ${ }^{1} \mathrm{H}$ NMR spectroscopy (Fig. S22 in ESI†) with $10 \mathrm{~mol} \%$ of $\mathbf{1}(\boldsymbol{E})$. Upon adding

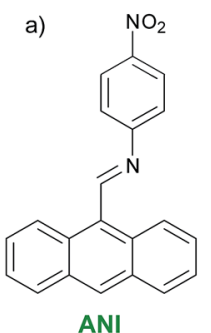

ANI

b) ANI and 1(E)

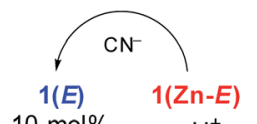

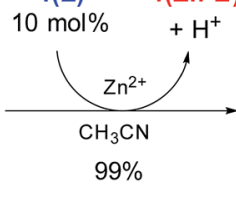

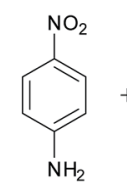

p-nitroaniline

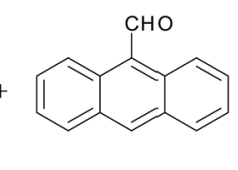

anthraldehyde

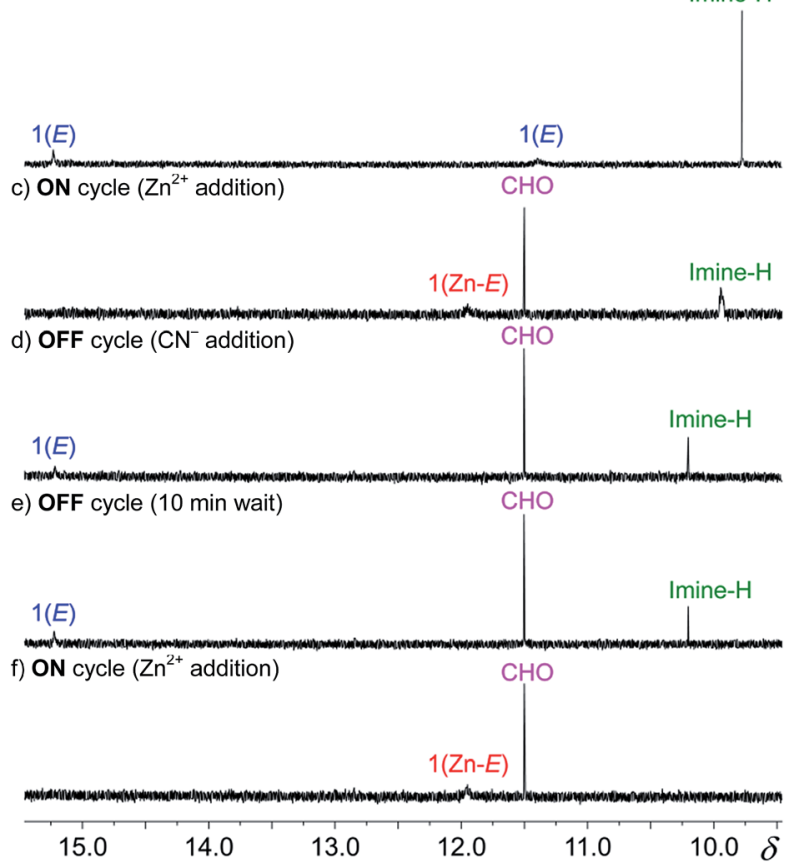

Fig. 4 (a) The on/off hydrolysis of ANI using reversible CCD of a catalytic amount of $1(E)$; the ${ }^{1} \mathrm{H}$ NMR spectra $\left(500 \mathrm{MHz}, \mathrm{CD}_{3} \mathrm{CN}\right.$ ) showing the imine and $\mathrm{NH}$ region of (b) $\mathrm{ANI}$ and $1(E)$; (c) hydrolysis of $\mathrm{ANI}$ and formation of anthraldehyde after the addition of $\mathrm{Zn}\left(\mathrm{ClO}_{4}\right)_{2}$; (d) hydrolysis turn "off" and restoration of $1(E)$ by addition of excess $\mathrm{CN}^{-}$; (e) mixture $10 \mathrm{~min}$ after the addition of $\mathrm{CN}^{-}$, demonstrating that catalysis is deactivated; and (f) the complete hydrolysis of ANI after the re-introduction of zinc(II).

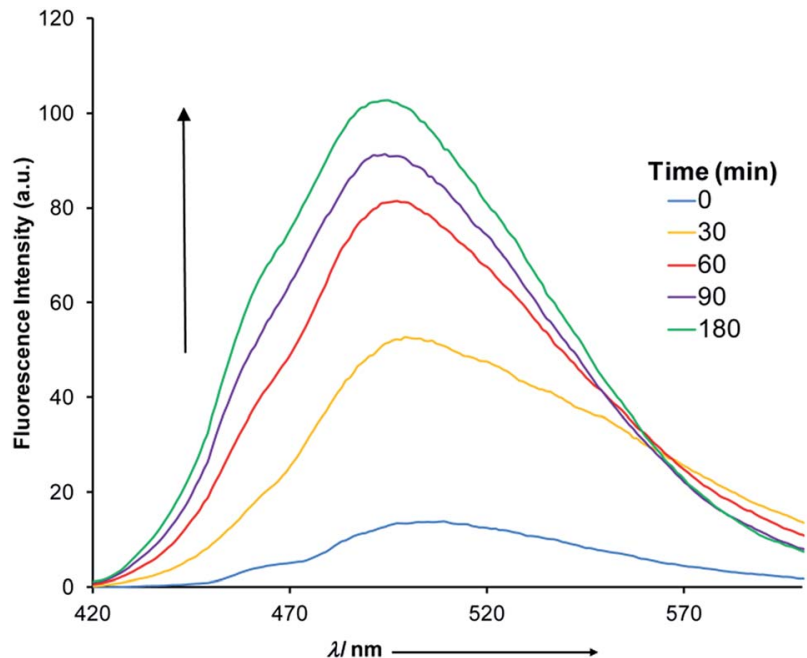

Fig. 5 The fluorescence spectra $\left(5 \times 10^{-5} \mathrm{M}, \mathrm{CH}_{3} \mathrm{CN}\right)$ obtained through the CCD mediated catalytic hydrolysis of ANI.

$10 \mathrm{~mol} \%$ of zinc(II) a catalytic amount of acid is produced through CCD that results in complete hydrolysis of ANI within 20 minutes. The maximum turnover number under these conditions is 10 , which means that at best each proton is now leading to 10 outputs! This signal enhancement process was also followed using fluorometry (Fig. 5). Upon the addition of $10 \mathrm{~mol} \%$ of zinc(II) to a $1: 1$ mixture of $\mathbf{1}(E)$ and ANI a steady increase in fluorescence was observed $(\lambda=522 \mathrm{~nm})$, which reached saturation after 180 minutes. $^{22}$

Next we took advantage of the reversible nature of CCD (Fig. S17 in ESI $\dagger$ ) to regulate the catalysis and toggle it between the "on" and "off" states. To follow this process we focused on the diagnostic imine and aldehyde proton signals of ANI and the anthraldehyde product, respectively (Fig. 4a). The initial mixture (Fig. 4b) shows the characteristic imine signal of ANI at $\delta=9.77 \mathrm{ppm}$, and the hydrazone and imidazole $\mathrm{NH}$ proton signals of $\mathbf{1}(E)$ (catalytic amount) ${ }^{23}$ at $\delta=15.25$ and $11.38 \mathrm{ppm}$, respectively. The addition of $\mathrm{Zn}\left(\mathrm{ClO}_{4}\right)_{2}$ to the mixture affords $\mathbf{1}(\mathbf{Z n}-\boldsymbol{E})$, with its characteristic imidazolyl resonance at $\delta=11.93$ ppm (Fig. 4c). The concomitant release of acid results in the hydrolysis of the imine bond and production of anthraldehyde, which results in a signal at $\delta=11.50 \mathrm{ppm}$ that grows over time. ${ }^{24}$ The catalysis was turned "off" with the addition of excess $\mathrm{CN}^{-}$(5 equiv.), which effectively demetalates $\mathbf{1}(\mathbf{Z n}-\boldsymbol{E})$ and restores $\mathbf{1}(\boldsymbol{E})$, thus stopping the catalytic cycle (Fig. $4 \mathrm{~d}) .^{25}$ This mixture was monitored for an additional 10 minutes to ensure that the ${ }^{1} \mathrm{H}$ NMR spectrum does not change during the "off" state (Fig. 4e). The hydrolysis can then be turned back "on" with the reintroduction of excess $\mathrm{Zn}\left(\mathrm{ClO}_{4}\right)_{2}$ (7 equiv.), which results in the complete hydrolysis of ANI within a few minutes.

\section{Conclusions}

We have demonstrated how coordination-coupled deprotonation can be used in signaling and catalysis driven signal amplification. These processes are possible because CCD in $\mathbf{1}(\boldsymbol{E})$ 
leads to the acidification of the solution, which when coupled with $\mathrm{pH}$ sensitive fluorophores leads to fluorescence turn "on". This was demonstrated with the activation of a new BODIPY dye (MBD) that led to a 1000-fold increase in emission intensity. More importantly, the reversible CCD process was used in regulating signal enhancement by turning the catalytic hydrolysis of ANI "on" and "off" using a metalation/demetalation cycle. We plan to continue with the development of multicomponent switchable systems, and further complicate the processes they can accomplish by using switches that can be activated by orthogonal inputs. ${ }^{26}$ We hypothesize that this methodology will lead the way towards chemical systems ${ }^{7}$ with biological level complexity.

\section{Acknowledgements}

We would like to acknowledge the support of the National Science Foundation CAREER program (CHE-1253385), and the Donors of the American Chemical Society Petroleum Research Fund (51842-DNI4). We gratefully acknowledge Prof. Richard Staples (Michigan State University) for X-ray data.

\section{Notes and references}

1 B. D. Gomperts, I. M. Kramer and P. E. R. Tatham, in Signal Transduction, Academic Press, Waltham, MA, USA, 2nd edn, 2009.

2 (a) A. Boiteux and B. Hess, Philos. Trans. R. Soc., B, 1981, 293, 5-22; (b) M. D. Brand, J. Exp. Biol., 1997, 200, 193-202; (c) C. B. Newgard, M. J. Brady, R. M. O'Doherty and A. R. Saltiel, Diabetes, 2000, 49, 1967-1977.

3 (a) J.-M. Lehn, Chem.-Eur. J., 2000, 6, 2097-2102; (b) V. E. Campbell, X. de Hatten, N. Delsuc, B. Kauffmann, I. Huc and J. R. Nitschke, Nat. Chem., 2010, 2, 684-687; (c) A. G. Salles, S. Zarra, R. M. Turner and J. R. Nitschke, J. Am. Chem. Soc., 2013, 135, 19143-19146.

4 (a) G. M. Whitesides and R. F. Ismagoliv, Science, 1999, 284, 89-92; (b) J.-M. Lehn, Science, 2002, 295, 2400-2403.

5 J.-M. Lehn, Angew. Chem., Int. Ed., 2013, 52, 2836-2850.

6 (a) A. P. de Silva, H. Q. N. Gunaratne and C. P. McCoy, Nature, 1993, 364, 42-44; (b) F. M. Raymo, Adv. Mater., 2002, 14, 401414; (c) F. M. Raymo, R. J. Alvarado, S. Giordani and M. A. Cejas, J. Am. Chem. Soc., 2003, 125, 2361-2364; (d) A. P. de Silva and S. Uchiyama, Nat. Nanotechnol., 2007, 2, 399-410; (e) V. Balzani, A. Credi and M. Venturi, Chem.Eur. J., 2008, 14, 26-39.

7 F. R. Ludlow and S. Otto, Chem. Soc. Rev., 2008, 37, 101-108. 8 (a) E. R. Kay, D. A. Leigh and F. Zerbetto, Angew. Chem., Int. Ed., 2007, 46, 72-191; (b) V. Balzani, A. Credi and M. Venturi, in Molecular Devices and Machines-Concepts and Perspectives for the Nanoworld, Wiley-VCH, Weinheim, 2008; (c) B. L. Feringa and W. R. Browne, in Molecular Switches, Wiley-VCH, Weinheim, 2nd edn, 2011; (d) A. Coskun, M. Banaszak, R. D. Astumian, J. F. Stoddart and B. A. Grzybowski, Chem. Soc. Rev., 2012, 41, 19-30.

9 (a) H. J. Yoon, J. Kuwabara, J.-H. Kim and C. A. Mirkin, Science, 2010, 330, 66-69; (b) R. S. Stoll and S. Hecht,
Angew. Chem., Int. Ed., 2010, 49, 5054-5075; (c) J. Wang and B. L. Feringa, Science, 2011, 331, 1429-1432; (d) M. J. Wiester, P. A. Ulmann and C. A. Mirkin, Angew. Chem., Int. Ed., 2011, 50, 114-137; (e) M. Schmittel, S. De and S. Pramanik, Angew. Chem., Int. Ed., 2012, 51, 38323836; ( $f$ ) V. Blanco, A. Carlone, K. D. Hänni, D. A. Leigh and B. Lewandowski, Angew. Chem., Int. Ed., 2012, 51, 5166-5169; (g) D. Wilson and N. R. Branda, Angew. Chem., Int. Ed., 2012, 51, 5431-5434.

10 (a) S. M. Landge and I. Aprahamian, J. Am. Chem. Soc., 2009, 131, 18269-18271; (b) X. Su and I. Aprahamian, Org. Lett., 2011, 13, 30-33; (c) S. M. Landge, E. Tkatchouk, D. Benitez, D. A. Lanfranchi, M. Elhabiri, W. A. Goddard and I. Aprahamian, J. Am. Chem. Soc., 2011, 133, 9812-9823; (d) X. Su, T. F. Robbins and I. Aprahamian, Angew. Chem., Int. Ed., 2011, 50, 1841-1844; (e) D. Ray, J. T. Foy, R. P. Hughes and I. Aprahamian, Nat. Chem., 2012, 4, 757-762; (f) X. Su, S. Voskian, R. P. Hughes and I. Aprahamian, Angew. Chem., Int. Ed., 2013, 52, 10734-10739; (g) X. Su and I. Aprahamian, Chem. Soc. Rev., 2014, 43, 1963-1981; (h) L. Tatum, X. Su and I. Aprahamian, Acc. Chem. Res., 2014, 47, 1214-1224.

11 (a) L. Zhu and E. V. Anslyn, Angew. Chem., Int. Ed., 2006, 45, 1190-1196; (b) M. Avital-Shmilovici and D. Shabat, Soft Mater., 2010, 6, 1073-1080; (c) P. Scrimin and L. J. Prins, Chem. Soc. Rev., 2011, 40, 4488-4505.

12 (a) Q. Wu and E. V. Anslyn, J. Am. Chem. Soc., 2004, 126, 14682-14683; (b) M. S. Maser III, N. C. Gianneschi, C. G. Oliveri, C. L. Stern, S. T. Nguyen and C. A. Mirkin, J. Am. Chem. Soc., 2007, 129, 10149-10158; (c) H. J. Yoon and C. A. Mirkin, J. Am. Chem. Soc., 2008, 130, 11590-11591; (d) A. L. Garner, F. Song and L. Koide, J. Am. Chem. Soc., 2009, 131, 5163-5171; (e) E. Sella, A. Lubelski, J. Klafter and D. Shabat, J. Am. Chem. Soc., 2010, 132, 3945-3952; $(f)$ E. Sella, R. Weinstain, R. Erez, N. Z. Burns, P. S. Baran and D. Shabat, Chem. Commun., 2010, 46, 6575-6577; $(g)$ M. S. Baker and S. T. Phillips, J. Am. Chem. Soc., 2011, 133, 5170-5173; (h) R. Bonomi, A. Cazzolaro, A. Sansone, P. Scrimin and L. J. Prins, Angew. Chem., Int. Ed., 2011, 50, 2307-2312; (i) H. Mohapatra and K. M. Schmid, Chem. Commun., 2012, 48, 3018-3020.

13 A. Mustafa, Science, 1950, 112, 440.

14 Compound $\mathbf{1}(\boldsymbol{E})$ was synthesized following the procedure reported in ref. $10 e$.

15 Crystal data for $\mathbf{1}(E)$ (CCDC 862857): $\mathrm{C}_{16} \mathrm{H}_{15} \mathrm{~N}_{5} \mathrm{O}_{2}, M=$ 309.33, monoclinic, $a=11.6410(8) \AA, b=8.7512(6) \AA$ А $c=$ 14.7356(10) $\mathrm{A}, \alpha=90.00^{\circ}, \beta=92.5980(10)^{\circ}, \gamma=90.00^{\circ}, V$ $=1499.61(18) \AA^{3}, T=173(2) \mathrm{K}$, space group $P 21 / c, Z=4$, 11726 reflections measured, 2739 independent reflections $\left(R_{\text {int }}=0.0292\right)$. The final $R_{1}$ values were $0.0453(I>2 \sigma(I))$. The final $w R\left(F_{2}\right)$ values were $0.1115(I>2 \sigma(I))$. The final $R_{1}$ values were 0.0544 (all data). The final $w R\left(F_{2}\right)$ values were 0.1191 (all data).

16 Crystal data for 1(Zn-E) (CCDC 990962): $\left(\mathrm{C}_{18} \mathrm{H}_{19} \mathrm{~N}_{6} \mathrm{O}_{3} \mathrm{Zn}\right)$. $0.5\left(\mathrm{C}_{2} \mathrm{H}_{3} \mathrm{~N}\right) \cdot\left(\mathrm{ClO}_{4}\right), M=552.74$, monoclinic, $a=22.782(2)$ $\AA, b=7.5608(8) \AA, c=26.996(3) \AA, \alpha=90.00^{\circ}, \beta=$ $102.9420(10)^{\circ}, \gamma=90.00^{\circ}, V=4531.9(8) \AA^{3}, T=173(2) \mathrm{K}$, 
space group $C 2 / c, Z=8,18054$ reflections measured, 4252 independent reflections $\left(R_{\text {int }}=0.0710\right)$. The final $R_{1}$ values were $0.0678(I>2 \sigma(I))$. The final $w R\left(F_{2}\right)$ values were 0.1595 $(I>2 \sigma(I))$. The final $R_{1}$ values were 0.1222 (all data). The final $w R\left(F_{2}\right)$ values were 0.1888 (all data).

17 Z. R. Grabowski, K. Rotkiewicz and W. Rettig, Chem. Rev., 2003, 103, 3899-4039.

18 A. P. de Silva, H. Q. N. Gunaratne, T. Gunnlaugsson, A. J. M. Huxley, C. P. McCoy, J. T. Rademacher and T. E. Rice, Chem. Rev., 1997, 97, 1515-1566.

19 When zinc(II) is added to MBD (Fig. S33 in ESI $\dagger$ ) no appreciable increase in emission is observed confirming that protonation results from CCD. Having the morpholinyl group is important as replacing it with a dimethyl amino group results in a false turn "on" with zinc(II).

20 This value is comparable to those obtained with various zinc(II) sensors in organic solvents: (a) J.-S. Wu, W.-M. Liu, X.-Q. Zhang, F. Wang, P.-F. Wang, S.-L. Tao, X.-H. Zhang, S.-K. Wu and S.-T. Lee, Org. Lett., 2007, 9, 33-36; (b) D. Y. Lee, N. Singh, M. J. Kim and D. O. Jang, Tetrahedron, 2010, 66, 7965-7969; (c) J. Cao, C. Zhao, X. Wang, Y. Zhang and W. Zhu, Chem. Commun., 2012, 48, 9897-9899.

21 (a) J. H. Clements and S. E. Webber, Macromolecules, 2004, 37, 1531-1536; (b) E. M. Pérez, D. T. F. Dryden, D. A. Leigh, G. Teobaldi and F. Zerbetto, J. Am. Chem. Soc., 2004, 126,
12210-12211; (c) D. A. Leigh, M. A. F. Morales, E. M. Pérez, J. K. Y. Wong, C. G. Saiz, A. M. Z. Slawin, A. J. Carmichael, D. M. Haddleton, A. M. Brouwer, W. J. Buma, G. W. H. Wurpel, S. Léon and F. Zerbetto, Angew. Chem., Int. Ed., 2005, 44, 3062-3067.

22 No increase in emission is observed when ANI is treated with zinc(II) (Fig. S30 in ESI†) indicating that the CCD is required for the hydrolysis to occur.

$2320 \mathrm{~mol} \%$ was used in this case in order to observe the $\mathrm{NH}$ signals in the ${ }^{1} \mathrm{H}$ NMR spectrum.

24 The addition of zinc(II) to ANI resulted in no changes in the ${ }^{1} \mathrm{H}$ NMR spectrum (Fig. S29 in ESI $\dagger$ ) indicating that the CCD is required for the hydrolysis to occur.

25 The addition of a high concentration of $\mathrm{CN}^{-}$leads to a side (addition) reaction with the imine (Fig. S23 in ESI $\dagger$ ). In order to obtain a cleaner transformation we used TREN as the demetalation agent. This yielded a clean and reversible catalysis (Fig. S24 in ESI†); however, the partial consumption of the released proton by TREN upon reintroduction of zinc(II) to the mixture, significantly slowed down the reaction rate (i.e., hydrolysis completes in $6 \mathrm{~h}$ ). This also means that now we have a larger turnover number, because less protons are available for catalysis.

26 C.-H. Wong and S. C. Zimmerman, Chem. Commun., 2013, 49, 1679-1695. 